\title{
Modulation of cell recruitment by anti-inflammatory agents in antigen-induced arthritis
}

\author{
M J López-Armada, O Sánchez-Pernaute, R Largo, I Diez-Ortego, I Palacios, J Egido, \\ G Herrero-Beaumont
}

Ann Rheum Dis 2002;61:1027-1030

Objective: To study the effect of meloxicam (MXC) and diclofenac (DCF) on the recruitment of leucocytes during acute experimental arthritis.

Methods: Rabbits with antigen-induced arthritis were treated with $M X C, D C F$, or not treated. After 48 hours, synovial fluid (SF) leucocyte influx and prostaglandin $E_{2}$ $\left(\mathrm{PGE}_{2}\right.$ ) levels were evaluated. Interleukin 8 (IL8) and monocyte chemotactic peptide-1 (MCP-1) expression and synthesis were studied in the inflamed tissues.

Results: Arthritic knees showed synovial effusion with a high leucocyte count and $\mathrm{PGE}_{2}$ concentration, and an increased expression of IL8 and MCP-1. Both non-steroidal anti-inflammatory drugs (NSAIDs) reduced $\mathrm{PGE}_{2}$ levels and the polymorphonuclear cell (PMN) concentration in SF, while the mononuclear cell (MN) concentration was unchanged in the treated groups in comparison with controls. A definite reduction of IL8 levels was obtained with the treatments, but the drugs did not prevent the up regulation of MCP-1.

Conclusion: The effect of these NSAIDs in acute arthritis may be related to the down regulation of IL8 production. The results suggest a differential effect of anti-inflammatory drugs on PMN and $M N$ recruitment to the joint.

$\mathrm{T}$ he contribution of chemokines to arthritis progression is widely recognised. ${ }^{1}$ Circulating leucocytes are recruited to the inflammatory site by the local production of chemokines, such as interleukin 8 (IL8) and monocyte chemotactic peptide-1 (MCP-1), which promote cell activation and proliferation. Both chemokines are overexpressed in the rheumatoid synovial tissue and their expression correlates with the severity of leucocyte infiltration. ${ }^{2}$

Non-steroidal anti-inflammatory drugs (NSAIDs) attenuate the acute inflammatory reaction and impair proinflammatory events dependent on neutrophils. ${ }^{3}$ The main mechanism of action of NSAIDs is inhibition of cyclo-oxygenase (COX), responsible for prostaglandins (PGs) biosynthesis. COX-1 is theoretically responsible for the homoeostatic functions of PGs, whereas COX-2 appears critical in $\mathrm{PGE}_{2}$ production during inflammation.

Some chemokine encoding genes may be $\mathrm{PGE}_{2}$ "sensitive", explaining the role of eicosanoids in migration. ${ }^{45}$ Our work aimed at exploring in vivo the consequences of the administration of COX inhibitors on chemokine-induced recruitment to the inflamed synovial tissue.

\section{METHODS}

\section{Experimental procedures}

Antigen arthritis was induced in ovalbumin preimmunised rabbits. ${ }^{26}$ Animals were divided into three experimental groups: non-treated rabbits $(n=16)$, meloxicam (MXC) treated (Boehringer Ingelheim) $(4 \mathrm{mg} / \mathrm{kg} / \mathrm{day}, \mathrm{n}=14)$ and diclofenac (DCF) treated (Sigma) $(5 \mathrm{mg} / \mathrm{kg} / 8 \mathrm{~h}, \mathrm{n}=14)$. Drugs were intramuscularly injected from 24 hours before the intraarticular injection until the animals were killed, 48 hours after the intra-articular injection. Eight healthy age matched animals were employed as controls.

\section{Determination of $\mathrm{PGE}_{2}$ in synovial fluid}

$\mathrm{PGE}_{2}$ concentration in the synovial fluid (SF) was determined by $\mathrm{PGE}_{2}$ enzyme immunoassay (Assay Designs, Inc).

\section{Identification of recruited cells and chemokines in the synovial membrane}

Paraffin embedded synovial membrane (SM) was stained with haematoxylin and eosin. A $0-3$ points scoring scale estimated the density of leucocyte populations.

Immunoreactivity to IL8 and MCP-1 was assessed by peroxidase techniques. ${ }^{2}$ The density of IL8 and MCP-1 staining was scored $0-4$.

\section{RT-PCR studies}

Total RNA from the SM was isolated, reverse transcribed and amplified with Access RT-PCR System (Promega), ${ }^{2}$ employing specific primers of rabbit IL8 and MCP- $1 .^{2}$

\section{Statistical analysis}

Data were expressed as mean (SEM). Descriptive statistics, analysis of variance test, and comparison of means by independent $t$ test were carried out. Differences were considered significant for $\mathrm{p}<0.05$.

\section{RESULTS}

Infiltration of leucocytes and production of $\mathrm{PGE}_{2}$

Untreated rabbits showed a large synovial effusion that was reduced by MXC treatment, but not by DCF (table 1). A high cell concentration was found in the SF in the untreated group ( $80 \%$ of the total cells were polymorphonuclear cells (PMN)). Only MXC administration diminished total cell count and PMN concentration (table 1). None of the drugs diminished the SF MN influx compared with the untreated group (table 1).

Tissue damage was partially prevented by both NSAIDs (web extra fig Wl). MXC treated rabbits showed a diminution in the PMN infiltration. DCF did not have a significant effect. Neither MXC nor DCF modified SM MN cell infiltration (table 1).

Abbreviations: COX, cyclo-oxygenase; DCF, diclofenac; IL, interleukin; MCP-1, monocyte chemotactic peptide-1; MN, mononuclear cells; MXC, meloxicam; NSAIDs, non-steroidal anti-inflammatory drugs; $\mathrm{PGE}_{2}$, prostaglandin $\mathrm{E}_{2} ; \mathrm{PMN}$, polymorphonuclear cells; $\mathrm{SF}$, synovial fluid; $\mathrm{SM}$, synovial membrane 
Table 1 DCF and MXC effect on leucocyte infiltration and $\mathrm{PGE}_{2}$ production. Values are shown as mean (SEM)

\begin{tabular}{lllllll}
\hline & $\begin{array}{l}\text { SF volume } \\
(\mu \mathrm{l})\end{array}$ & $\begin{array}{l}\text { SF PGE } \\
(\mathrm{ng} / \mathrm{ml})\end{array}$ & $\begin{array}{l}\text { SF PMN } \\
\left(\text { cells } / \mathrm{ml} \times 10^{-6}\right)\end{array}$ & $\begin{array}{l}\text { SF MN } \\
\left(\text { cells } / \mathrm{ml} \times 10^{-6}\right)\end{array}$ & $\begin{array}{l}\text { SM PMN } \\
(0-3)\end{array}$ & $\begin{array}{l}\text { SM MN } \\
(0-3)\end{array}$ \\
\hline Non-treated & $324(24)$ & $16(4)$ & $88(13)$ & $22(3)$ & $1.8(0.4)$ & $0.8(0.3)$ \\
MXC & $177(29)^{*}$ & $3(0.4)^{*}$ & $46(8)^{*}$ & $21(3)$ & $0.5(0.2)^{*}$ & $1.2(0.3)$ \\
DCF & $229(53)$ & $1.7(0.4)^{*} \dagger$ & $54(10)$ & $32(9)$ & $1.3(0.3)$ & $1.4(0.2)$ \\
\hline \multirow{2}{*}{$p<0.05$ v untreated rabbits; $\dagger p<0.05 v M X C}$. & & &
\end{tabular}
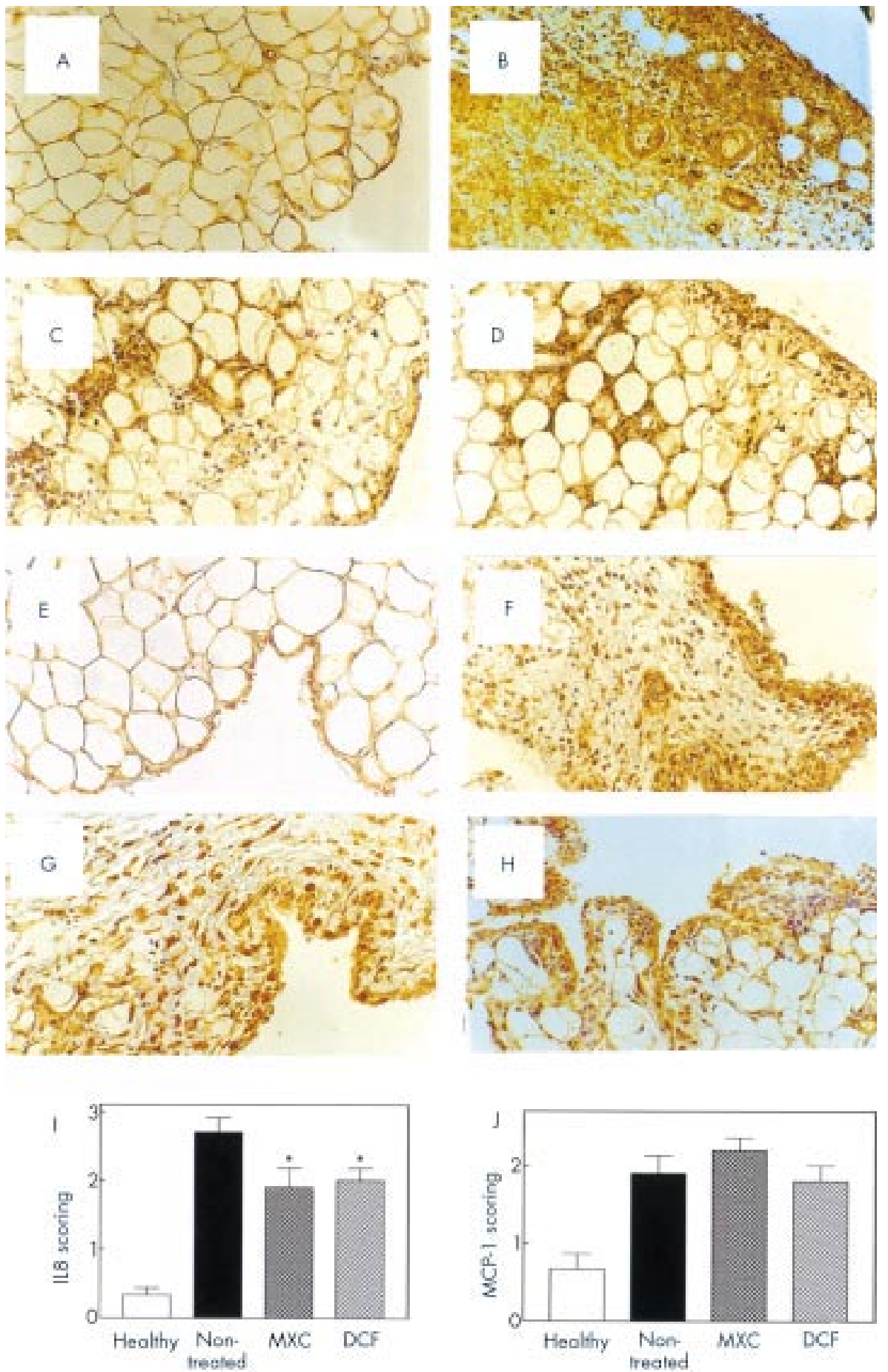

Figure 1 IL8 (A-D) and MCP-1 (E-H) SM immunostaining ( $\times 200)$. Healthy controls (A, E); untreated group $(B, F)$; MXC treated rabbits (C, G); DCF treated rabbits $(D, H)$. Semiquantitative scoring for IL8 (I) and MCP-1 (J) of the different groups (* $p<0.05 v$ non-treated). 
A
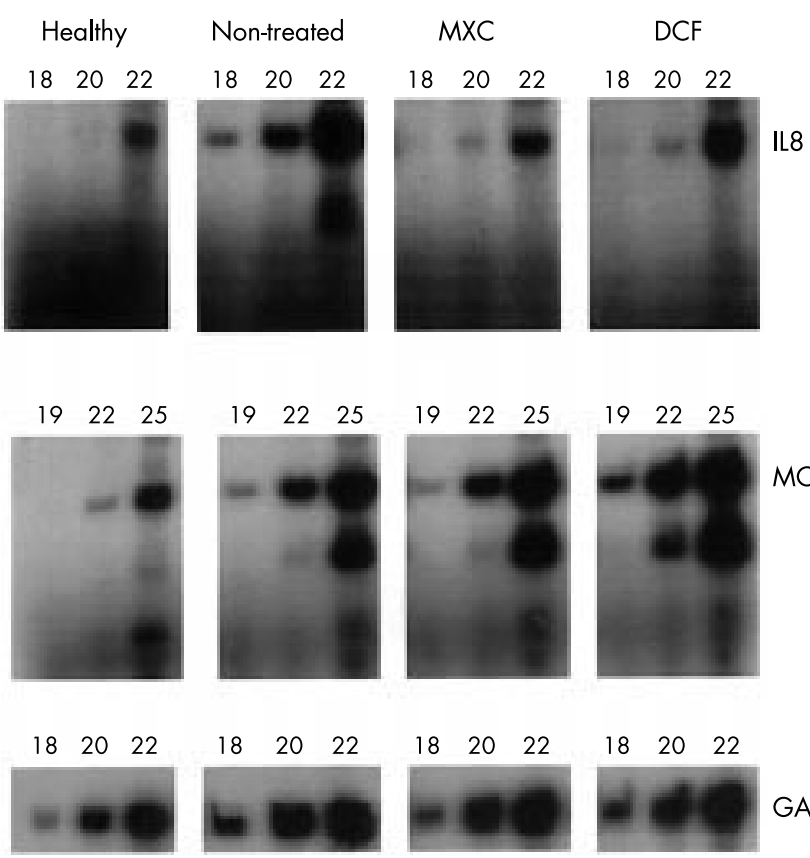

GADPH

MCP-1
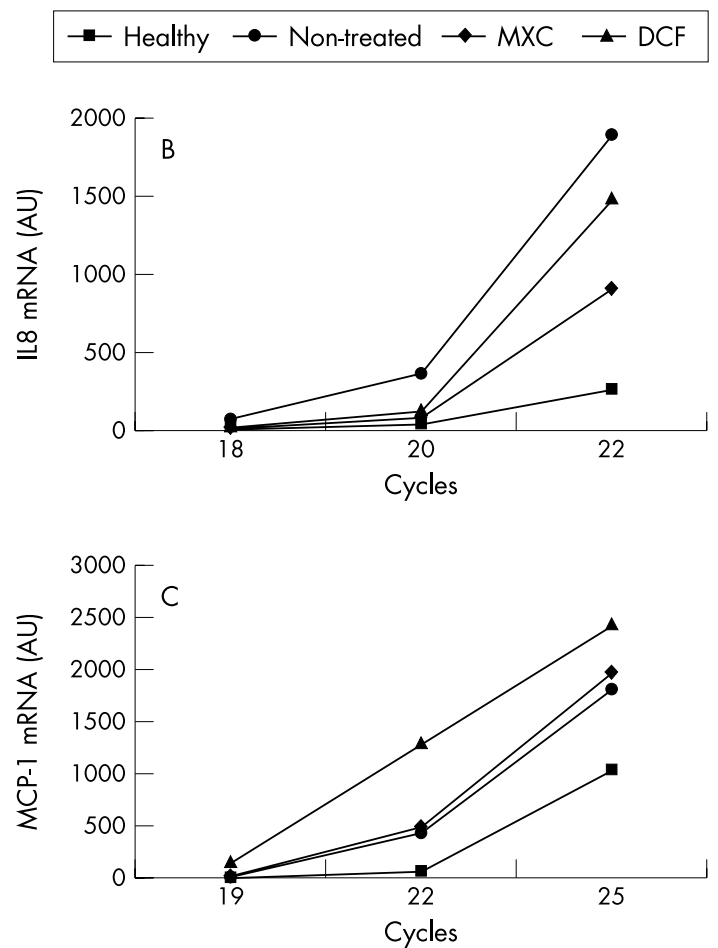

Figure 2 IL8 and MCP-1 expression in SM. Representative RT-PCR experiment (A). Densitometry of IL8 (B) and MCP-1 (C) bands corrected by glyceraldehyde-3-phosphate dehydrogenase (GAPDH) expression.

Increased levels of $\mathrm{PGE}_{2}$ were found in the $\mathrm{SF}$ of untreated rabbits ( $16(4) \mathrm{ng} / \mathrm{ml}$ ). Both NSAIDs reduced $\mathrm{PGE}_{2}$ concentration. DCF induced a greater fall in PGE, levels than MXC.

\section{IL8 and MCP-1 immunolocalisation}

IL8 and MCP-1 followed a similar pattern of distribution. Mononuclear cells and the lining layer were strongly positive (fig 1). Extracellular IL8 was largely detected in neutrophilic collections and in the endothelium. Both NSAIDs down regulated IL8 immunoreactivity (figs 1A-D, I) mainly by a reduction in the areas corresponding to neutrophilic collections. For the MCP-1 signal, there were no differences between the groups (figs $1 \mathrm{E}-\mathrm{H}, \mathrm{J}$ ).

\section{IL8 and MCP-1 gene expression in the SM}

The high immunoreactivity to IL8 and MCP-1 in the injured tissues was accompanied by an enhancement in the expression of both genes. IL8 expression was reduced with both treatments, although it was more evident in MXC treated animals. None of the drugs diminished the MCP-1 message (fig 2).

\section{DISCUSSION}

We have studied the effect of two NSAIDs on cell infiltration, local PGE , $_{2}$ and IL8 and MCP- 1 synovial expression in a model of experimental arthritis. The clinical benefit of both drugs was related to a diminution of joint swelling, reduction of the effusion and infiltration by PMN. Only MXC treatment showed significant effects on SF volume and PMN infiltration. The MXC group showed a smaller diminution of $\mathrm{PGE}_{2}$ levels in SF than did DCF. Our results showed a lack of correlation between $\mathrm{PGE}_{2}$ inhibition and clinical improvement. Previous evidence has shown that $\mathrm{PGE}_{2}$ depletion may lead to an up regulation of several proinflammatory mediators, such as tumour necrosis factor $\alpha$ and ILI $\beta$ in the inflamed SM. ${ }^{6}$ COX derived eicosanoids exert some regulating functions important for the resolution of inflammation.

We found a differential regulation of PMN and MN migration by the NSAIDs. Cell count and density scoring in each group paralleled the respective induction of the chemokines studied. NSAIDs action appeared selective for PMN influx, and related to a down regulation of IL8 local expression. MCP-1 expression and synthesis remained largely activated in the SM of treated groups. This may explain why both treatments increase MN density in the SM and SF. This is in agreement with previous data describing a lack of effect of NSAIDs at the chronic stage of this experimental disease, when inflammatory events are dominated by macrophages and lymphocytes. Recent unpublished data from our laboratory show that MXC and DCF further increase MCP-1 expression in IL1 $\beta$ stimulated synoviocytes. These and other data suggest that $\mathrm{PGE}_{2}$ may act as an MCP-1 repressor agent. ${ }^{8}$ This effect seems to be related to the $\mathrm{PGE}_{2}$ synthesis inhibition afforded by NSAIDs.

Our results indicate that a total $\mathrm{PGE}_{2}$ depletion may not be desirable. We have shown that NSAIDs down regulate IL8 production in antigen arthritis, but may favour the recruitment of MN. A full understanding of prostaglandin activities as stimulating or repressor factors of inducible genes is desirable to design a better therapeutic approach with NSAIDs in joint diseases.

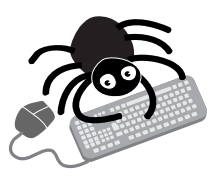

The synovium histopathology of rabbits with acute antigen arthritis is shown on the web at www.annrheumdis.com

\section{Authors' affiliations}

M J López-Armada, O Sánchez-Pernaute, R Largo, I Diez-Ortego, I Palacios, J Egido, G Herrero-Beaumont, Inflammation Research Unit, Fundación Jiménez Díaz, Universidad Autónoma, Madrid, Spain

Correspondence to: Dr G Herrero-Beaumont, Fundación Jiménez Díaz, Reyes Católicos, 228040 Madrid, Spain; gherrero@fjd.es

Accepted 14 May 2002 


\section{REFERENCES}

1 Arend WP. Physiology of cytokine pathways in rheumatoid arthritis. Arhtritis Rheum 2001:45:101-6.

2 Palacios I, López-Armada M, Hernández P, Sanchez-Pernaute O, Gutiérrez S, Miguélez R, et al. Tenidap decreases IL-8 and MCP-1 expression in the synovial tissue of rabbits with antigen arthritis and in cultured synovial cells. Clin Exp Immunol 1998;1 11:588-96.

3 Abramson SB, Weissmann G. The mechanisms of action of nonsteroidal antiinflammatory drugs. Arthritis Rheum 1989;32:1-9.

4 Agro A, Langdon C, Smith F, Richards CD. PGE2 enhances IL-8 and IL-6 but inhibits GMCSF production by IL-1 stimulated human synovial fibroblasts in vitro. J Rheumatol 1996;23:862-8.

5 Standiford TJ, Kunkel SJ, Rolfe MW, Evanoff HL, Allen RM, Strieter RM. Regulation of human alveolar macrophage and blood monocyte-derived interleukin- 8 by PGE2 and dexamethasone. Am J Respir Cell Mol Biol 1992;6:75-81

6 Benito MJ, Sánchez-Pernaute O, López-Armada M, Hernández P, Palacios I, Egido J, et al. Cyclosporin A prevents the histologic damage of antigen arthritis without inducing fibrosis. Arthritis Rheum 2000;43:311-19

7 Gilroy D, Colville-Nash PR, Willis D, Chivers J, Paul-Clark MJ, Willoughby DA. Inducible cyclooxygenase may have anti-inflammatory properties. Nature Med 1999;5:698-701.

8 Schneider A, Harendza S, Zahner G, Jocks T, Wenzel U, Wolf G, et al. Cyclooxygenase metabolites mediate glomerular MCP-1 formation and monocyte recruitment in experimental glomerulonephritis. Kidney Int 1999;55:430-41.

\section{UNUSUAL AND MEMORABLE}

\section{Case Number 25: A butterfly rash}

Series editor: Gary D Wright

A 33 year old woman attended the rheumatology clinic for assessment of her cutaneous lupus. The diagnosis of cutaneous lupus had been made by her dermatologist five years beforehand; this was confirmed by biopsy. She subsequently developed a positive anti-DNA antibody at low titres, with negative extractable nuclear antigen, but had no other clinical symptoms of systemic lupus.

The figure shows one of several active cutaneous lupus lesions overlying a butterfly tattoo, which had predated any of her symptoms.

\section{Acknowledgement}

Photograph by IM Chalmers, University of Manitoba, RR149, 800 Sherbrook Street, Winnipeg, MB Canada R3A 1M4. Tel. 2047872208.

J M G Canvin

Department of Rheumatology, University of Manitoba, RR 149, 800 Sherbrook Street, Winnipeg, MB Canada, R3A 1M4

S Silver

Department of Dermatology, University of Manitoba, RR 149

800 Sherbrook Street, Winnipeg, MB Canada, R3A 1M4 Correspondence to: Dr J M G Canvin; elgabal@cc.umanitoba.ca

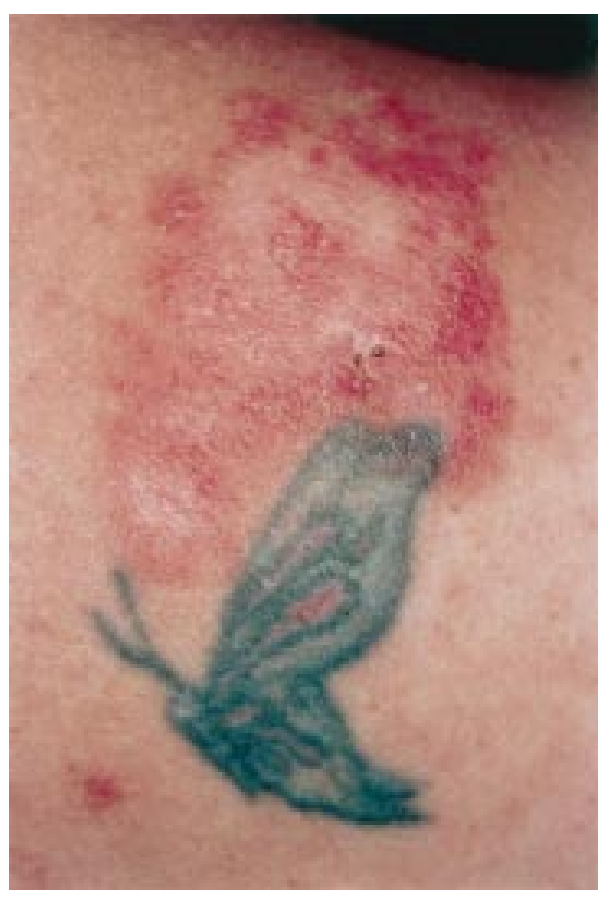

